\title{
A PREPARAÇÃO FÍSICA DE DOIS ATLETAS DE JUDÔ DE ALTO NÍVEL ESTUDO DE CASO
}

Felipe Leal de Paiva Carvalho

Estélio Henrique Martin Dantas

Mauro Cesar Gurgel de Alencar Carvalho

Filipe Terada

Tiago Takara

\section{Resumo}

O presente estudo tem por objetivo apresentar o processo de treinamento adotado e os resultados obtidos por dois atletas de judô da categoria de peso ligeiro (até 59,999 kg) do Estado de São Paulo (Brasil), entre os meses de agosto a dezembro de 2001. O planejamento foi adaptado ao calendário, às demandas do judô e aos objetivos e necessidades dos judocas e da modalidade. $\mathrm{O}$ macrociclo dividiu-se em quatro mesociclos e culminou com o pico de rendimento no momento oportuno. Os principais resultados foram: a) maior número de vitórias nos principais torneios regionais e nacionais $(\mathrm{B} \%=71,42) ; \mathrm{b})$ melhoria da força máxima $(\mathrm{B} \%=21,28, \mathrm{p}=0,001<0,05) ; \mathrm{c})$ porcentagem de gordura corporal próximo da média da seleção nacional de 2002); d) manutenção do peso no limite máximo da categoria (60 kg).

\section{Palavras-Chave}

Judô; Treinamento; Planejamento.

\section{PHISICAL PREPARATION OF TWO HIGH PERFORMANCE JUDO ATHLETES A CASE STUDY}

Felipe Leal de Paiva Carvalho

Estélio Henrique Martin Dantas

Mauro Cesar Gurgel de Alencar Carvalho

Filipe Terada

Tiago Takara

\begin{abstract}
The purpose of this study was to show the training process adopted for two judo athletes from São Paulo (Brazil), between august and December of 2001 and the results. The planning was adapted to the calendar, the judo needs and the objectives and necessities of the athletes. The macrocycle was divided in four phases and had the peak at the opportune moment. Exercises had been adapted to the trainings specify of judo. Main results: a) Improvement in numbers of victories in the main regional and national tournaments $(B \%=71,42)$; b) Improvement of the maximum $\operatorname{strength}(B \%=21,28, p=0,001<0,05)$ : $c)$ Percentage of corporal fat close to Brazilian team; d) maintenance of the weight in the maximum limit of the category $(60 \mathrm{~kg})$.
\end{abstract}

\section{Key-Words}

Judo; Training; Planning. 


\section{INTRODUÇÃO}

A sistematização do treinamento no judô é complexa porque, se tratando de um desporto, que combina diversas capacidades motoras, se caracteriza como aberto e acíclico, com ampla variedade de técnicas (golpes) e táticas, diferentes estilos de lutadores e variação do tempo de descanso e total de luta (FRANCHINI, 2001).

As participações com sucesso em competições de judô dependem de elevado nível técnico-tático do atleta, tendo como suporte resistência aeróbica, potência e capacidade anaeróbica, força e flexibilidade (LITTLE, 1991). Estudos têm apresentado distintas formas de testes e exercícios para o judô (LIMA, et al. 2004); modelos de periodização do treinamento para atletas (TSCHIENE, 1987) e para o judô (AZEVEDO et al. 2004; GIL'AD; 1998; SILVA; 1988) e a estrutura temporal das lutas (CASTARLENAS; PLANAS, 1997).

Os aspectos fisiológicos da modalidade em momentos pré-competitivo e competitivo foram demonstrados por estudos que utilizaram testes laboratoriais e de campo (EBINE, et al. 1991; CALLISTER, et al. 1990; LITTLE, 1991; TAYLOR; BRASSARD, 1981). Um estudo de Franchini, et al. (1998), que analisou lutas propriamente ditas, encontrou um grande aumento da concentração de lactato sangüíneo. Em estudo realizado com atletas femininas da seleção brasileira de judô (FRANCHINI, et al. 2001), foram apresentadas algumas mudanças fisiológicas da potência e capacidade aeróbicas e anaeróbicas no decorrer dos treinamentos para os jogos pan-americanos. Sobre a mudança da composição corporal, causadas pela perda de peso durante curto período de tempo em treinamento e competição, os trabalhos de Kraemer et al. (2001) e Umeda et al. (2004) concluíram que pode afetar negativamente o rendimento.

Supondo que um maior número de relatos científicos, unindo o conhecimento das características fisiológicas com as práticas de preparação específicas do judô possa gerar conceitos vitais na busca de um caminho próprio sobre planejamento e treinamento físico para tal modalidade, esse trabalho tem com objetivo apresentar o desenvolvimento da preparação física aplicada em dois atletas de judô da categoria peso ligeiro (até $59,999 \mathrm{~kg}$ ) do Estado de São Paulo, entre os meses de agosto a dezembro de 2001, apontando a variável independente - metodologia, decisões tomadas e os exercícios utilizados assim como a variável dependente - resultados finais. 


\section{CASUÍSTICA E METAS}

Atleta 1 - Brasileiro 22 anos, 1,64 metros, $63 \mathrm{~kg}$, faixa preta $1^{\circ} \mathrm{DAN}$, categoria ligeiro, residente em São Paulo. Possui diversos títulos em nível estadual e já treinou junto à seleção brasileira. Atleta 2 Brasileiro 20 anos, 1,67 metros, $62 \mathrm{~kg}$, faixa preta $1^{\circ} \mathrm{DAN}$, categoria ligeiro, começando a se destacar em competições municipais e amistosos em São Paulo. Objetivos: Atleta1 - Integrar a Seleção Brasileira permanente e como competições principais os jogos abertos do interior e as seletivas regional e nacional para o mundial. Atleta 2 - Melhorar seu desempenho regional. Sua competição principal era a seletiva regional para a seleção brasileira.

Ambos os atletas consentiram em ter seus treinamentos apresentados na forma de artigo científico expresso em Termo de Participação Livre e Consentida.

\section{CALENDÁRIO}

O calendário das competições de judô no Brasil é bastante amplo, com torneios durante todo o ciclo anual de treinamento. Torneios municipais e regionais do estado de São Paulo são classificatórios para o estadual paulista que por sua vez é classificatório para o brasileiro. Existem também os classificatórios regionais e nacionais para a seleção brasileira permanente de judô. Os jogos brasileiros universitários e os jogos abertos do interior são considerados duas das mais importantes competições do Brasil.

Quadro 1- Calendário de competições

\begin{tabular}{|c|c|c|}
\hline Atleta1 & Data & Competição \\
\hline Inicio dos treinos & $06 / 08 / 2001$ & \\
\hline Competiçãol & $16 / 09 / 2001$ & Paulista \\
\hline Competição2 & $05 / 10 / 2001$ & Abertos do Interior* \\
\hline Competição3 & $27 / 11 / 2001$ & Seletiva regional \\
\hline Competição4 & $10 / 12 / 2001$ & Seletiva Nacional* \\
\hline Atleta2 & Data & Competição \\
\hline Inicio dos treinos & 06/08/2001 & \\
\hline Competiçãol & $16 / 09 / 2001$ & Paulista \\
\hline Competição2 & $27 / 11 / 2001$ & Seletiva regional* \\
\hline
\end{tabular}

Além das competições alvo já definidas (Quadro 1), os atletas deveriam participar também de alguns torneios preparatórios. Estas competições introdutórias tinham objetivos como a inserção gradativa do atleta no ritmo de competição, a classificação para outras provas, a observação do atleta em campo possibilitando redefinições de prioridades do treinamento em relação ao desempenho, o ganho de experiências positivas e o respeito dos oponentes (AZEVEDO et al. 2004). 


\section{MONTAGEM DO CICLO E MÉTODOS DE TREINAMENTO}

$\mathrm{Na}$ montagem dos ciclos, o macrociclo foi dividido em quatro mesociclos expostos na quadro II; como material para os treinos, tínhamos duas áreas de competição oficiais, uma sala de musculação e um ginásio; uma anamnese foi criada para o conhecimento dos atletas, de suas bagagens atléticas e rotinas de treino. Avaliação antropométrica e análise de testes realizados anteriormente contribuíram para a distribuição das cargas dentro dos microciclos de treinamento de acordo com as necessidades individuais de cada judoca.

A preparação física foi elaborada com base nas leis de adaptação do organismo humano, nos princípios da sobrecarga, da especificidade e das nas metodologias modernas de periodização (FORTESA DE LA ROSA, 2001), nas caracterizações fisiológicas e neurológicas da modalidade (FRANCHINI, 2001) e no calendário de competições para estabelecer o treinamento da forma mais racional possível.

Quadro 2- Macrociclo

\begin{tabular}{|c|c|c|c|c|}
\hline Macrociclo & & Pico 1 & & Pico 2 \\
\hline mesociclos & $\begin{array}{l}\text { Preparatório I } \\
\text { Incorporação }\end{array}$ & $\begin{array}{l}\text { Preparatório II } \\
\text { Específico }\end{array}$ & $\begin{array}{l}\text { Preparatório } \\
\text { III Força }\end{array}$ & $\begin{array}{l}\text { Competicão } \\
\text { Principal }\end{array}$ \\
\hline Objetivos & $\begin{array}{l}\text { 1-Introdução ao } \\
\text { treinamento físico } \\
\text { específico. } \\
\text { 2- Adaptação física e } \\
\text { psicológica ao } \\
\text { aumento das cargas de } \\
\text { treino }\end{array}$ & $\begin{array}{l}\text { Melhoria das } \\
\text { capacidades } \\
\text { específicas inerentes } \\
\text { àluta de judô: Força, } \\
\text { Velocidade, } \\
\text { Resistência. Potência }\end{array}$ & $\begin{array}{l}\text { Ganho de } \\
\text { força máxima } \\
\text { sem aumento } \\
\text { do peso } \\
\text { corporal. }\end{array}$ & $\begin{array}{l}\text { Atingir o melhor } \\
\text { desempenho no } \\
\text { momento } \\
\text { oportuno. }\end{array}$ \\
\hline microciclos & Tres & Seis & sSeis & Sete \\
\hline
\end{tabular}

\section{PREPARATÓRIO I}

Os exercícios foram baseados nas atividades dentro do tatame, de acordo às idéias da metodologia integradora que busca a melhora das capacidades com atividades específicas de luta (CASTARLENAS; SOLÉ 1997).

Para o treino da força específica, foi utilizado o exercício de puxar o $U k e^{l}$, finalizando com uma entrada de golpe. A velocidade foi treinada com $u c h i-k o m i^{2}$ das técnicas de projeção preferidas pelos lutadores e com trocas de pegada. A potência teve atenção especial: Treinada com diversos tipos de puxadas com a 
maior potência possível, puxadas pela faixa, puxadas pela manga e puxadas de gola e manga. Houve muita preocupação com a qualidade do movimento, pois se visava coordenar as alavancas corporais num rápido e forte movimento. A resistência aeróbia foi praticada com uchi-komi e joga-joga. Exercícios de contraste de força + velocidade foram praticados com uchi-komi.

\section{PREPARATÓRIO II}

Nesta fase houve um aumento inicial de volume e intensidade, os exercícios foram programados e executados dentro do tatame, com a máxima especificidade possível. Para tal, foram iniciados os treinos de projeção em potência máxima. A resistência anaeróbica foi treinada com lutas intervaladas e adaptações de ataque contra defesa, com máxima intensidade e descansos incompletos. A velocidade de pegada no quimono foi treinada com dois tipos de exercício:

1. Parado - com os dois atletas tentando a pegada o mais rápido possível ao comando do preparador físico.

2. Em movimento - um atleta tenta a pegada e o outro defende durante um tempo programado sem o comando técnico.

\section{PREPARATÓRIO III}

Nesta fase ocorreu uma diminuição do volume e o treino saiu do dojo. Como a força é capacidade fundamental para o desempenho no judô (FRANCHINI, 2001; LITTLE, 1991) tal valência física teve atenção especial neste momento, com exercícios de musculação: supino reto, agachamento e remada alta. A carga utilizada foi de $95 \%$ de 1RM (repetição máxima), com quatro a cinco séries de duas a três repetições e três a cinco minutos de descanso entre as séries. Também foi dada atenção especial à musculatura abdominal e da região lombar.

\footnotetext{
- Parceiro de treino

2 - Entrada de golpes com o parceiro parado
} 


\section{COMPETITIVO}

Ocorreu grande incremento do volume no inicio deste mesociclo, que diminuiu com o decorrer das semanas inversamente proporcional ao aumento da intensidade. Os gestos desportivos formaram a parte principal do treino e desenvolveram as solicitações fisiológicas da competição de judô. O metabolismo anaeróbico lático foi treinado com diversas formas de lutas intervaladas simulando um torneio, com descansos incompletos que também simulavam os tempos de competição (CASTARLENAS; PLANAS, 1997). Essa fase também visou manutenção das capacidades adquiridas, utilizando os exercícios já explicados anteriormente.

\section{RESULTADOS E DISCUSSÃO}

\section{Periodização Aplicada}

Quadro 3- Quantidade de sessões de treino, semanas e exercícios por mesociclo.

\begin{tabular}{|l|c|c|c|c|c|}
\hline & Incorporação & Específica & Forca & Principal & Total \\
\hline Semanas & 3 & 6 & 3 & 7 & 19 \\
\hline Sessões de treino & 9 & 18 & 9 & 21 & 57 \\
\hline Potência de puxada & 8 & 6 & 0 & 5 & 16 \\
\hline Velocidade de entradas & 5 & 8 & 0 & 10 & 23 \\
\hline Potência de quedas & 0 & 6 & 0 & 10 & 19 \\
\hline Intervalado de lutas & 0 & 7 & 0 & 16 & 23 \\
\hline Treinos de pegadas & 5 & 6 & 0 & 20 & 31 \\
\hline Treinos de musculação & 0 & 0 & 9 & 0 & 12 \\
\hline Força de puxada & 6 & 8 & 0 & 4 & 18 \\
\hline
\end{tabular}

A periodização montada apresenta-se no Quadro III, com as respectivas sessões de treino, tipos de exercício e quantidades de semanas por mesociclo. Como o primeiro objetivo do atletal eram os jogos abertos do interior e o atleta2 buscava o condicionamento geral, os dois primeiros mesociclos atingiram tais resultados com o aumento de rendimento e algumas vitórias. Após esse momento os lutadores tiveram uma semana de descanso profilática, criando assim condição favorável para o aumento da intensidade nos mesociclos seguintes (TSCHIENE, 1987), culminando no pico de rendimento exatamente nas competições alvo (seletivas abertas), alcançando todos os objetivos pré-estabelecidos. 


\section{GANHOS DE CONDICIONAMENTO FÍSICO}

A capacidade anaeróbica lática e a potência muscular parecem ser as variantes principais para o bom desempenho do atleta de judô (FRANCHINI, 2001; LITTLE, 1991; THOMAS, et al. 1989). Os exercícios dentro do tatame e os treinamentos com atletas da mesma categoria de peso durante treinamento respeitaram a proposta integradora (CASTARLENAS; SOLÉ, 1997), os tempos de luta e de descansos nos treinamentos foram semelhantes aos de competição respeitando a teoria da especificidade (Dantas, 2003), as séries de exercícios buscaram o desenvolvimento do sistema glicolítico de produção de energia e das capacidades necessárias ao sucesso em competição (FRANCHINI, 2001; CASTARLENAS; SOLE, 1997).

O treino de força neste estudo teve momentos distintos: Primeiro seguiu o modelo integrador (Castarlenas; SOLÉ, 1997) utilizando apenas atividades específicas que simulavam atividades de luta. Após este primeiro estágio, as avaliações de 1RM, as lutas e as conversas com os atletas mostraram que para alcançar melhor rendimento, deveriam melhorar a força em relação aos seus adversários, nos levando a um mesociclo de força máxima. Esta escolha diminuiu a probabilidade de ganho de massa muscular indesejado para atletas que se encontravam no limite máximo de peso da categoria.

Tabela 1- Comparação de teste e reteste de $1 \mathrm{RM}$ através do teste t pareado

\begin{tabular}{|c|c|c|}
\hline & Teste & Reteste \\
\hline Observações (n) & 6 & 6 \\
\hline Média & 62,5 & 75,8 \\
\hline Variância & 537,50 & 794,17 \\
\hline Curtose & $-1,31$ & $-1,71$ \\
\hline Assimetria & $-0,46$ & $-0,34$ \\
\hline Shapiro-Wilk & 0,6732 & 0,4762 \\
\hline Hipótese da diferença de média Diferença e & 0,05 & \\
\hline ganho entre as médias \% de ganho com o & $13,3 \mathrm{~kg}$ & \\
\hline treinamento & $+21,28 \%$ & \\
\hline gl & 5 & \\
\hline t crítico (uni-caudal) & 2,015 & \\
\hline t estatístico encontrado & 5,41 & \\
\hline p (uni-caudal) & 0,001 & \\
\hline
\end{tabular}

Atleta1: 1RM, no supino aumentou de $80 \mathrm{~kg}$ para $95 \mathrm{~kg}$; no agachamento aumentou de $90 \mathrm{~kg}$ para $110 \mathrm{~kg}$; na remada alta aumentou de $40 \mathrm{~kg}$ para $45 \mathrm{~kg}$.

Atleta2: 1RM, no supino aumentou de $65 \mathrm{~kg}$ para $75 \mathrm{~kg}$; no agachamento aumentou de $70 \mathrm{~kg}$ para $90 \mathrm{~kg}$; na remada alta aumentou de $30 \mathrm{~kg}$ para $40 \mathrm{~kg}$.

Os resultados obtidos no teste (antes do mesociclo de força) e reteste (depois desta fase) - Tabela I mostraram distribuições normais ao se analisarem seus momentos e o teste de Shapiro-Wilk ( $p>0,05)$. 
Observaram-se ganhos significativos de $21,28 \%$ de carga nos 3 exercícios testados, onde $\boldsymbol{p}=\mathbf{0 , 0 0 1}$ (unicaudal).

Os resultados obtidos nos testes de força quando comparados com as médias da avaliação da seleção brasileira de 2002 para a mesma categoria (quadro IV) e as respostas positivas dos atletas frente aos adversários sugerem que este planejamento para aumento de força em judocas peso ligeiro é eficiente.

Quadro 4- Comparação dos valores de força máxima

\begin{tabular}{lccc}
\hline \multicolumn{1}{c}{ 1RM } & Atletal Sel & Seleção Brasileira & Atleta \\
\hline Supino & $95 \mathrm{~kg}$ & $82 \mathrm{~kg}$ & $75 \mathrm{~kg}$ \\
Agachamento & $110 \mathrm{~kg}$ & $93 \mathrm{~kg}$ & $90 \mathrm{~kg}$ \\
\hline
\end{tabular}

Ao longo do período de treinamento os atletas conseguiram abaixar o peso corporal e ficar em torno dos $60 \mathrm{~kg}$, dessa forma não precisaram perder peso as vésperas das competições, atingindo assim mais um objetivo. Alguns autores relatam que a perda de peso pré-competição muito comum a lutadores está diretamente relacionada à diminuição da massa magra, perda de força, de capacidade anaeróbica e ainda aumento no tempo de recuperação após uma série de lutas, diminuindo o desempenho durante um torneio (Kraemer, et al. 2001; Umeda, et al. 2004). Portanto a manutenção do peso corporal dentro do limite da categoria parece ser de suma importância para lutadores de alto nível.

O perfil da composição corporal de atletas de judô está bem descrito na literatura científica (FRANCHINI, 2001; LITTLE, 1991), com base nestes dados, um baixo percentual de gordura se mostra favorável ao alto desempenho principalmente pelo judô ser dividido em categorias de peso.

Em tabela proposta pó (Franchini (2001, p. 88) são apresentados diversos estudos de composição corporal com judocas masculinos de seleções nacionais de diferentes países, destacamos a avaliação da seleção brasileira nos jogos Pan-Americanos de 1999 que teve 8\% em média de gordura corporal. Comparando os resultados alcançados neste trabalho com a média da seleção brasileira de 2002 proposta para a categoria de peso ligeiro temos:

Quadro 5- Percentagem de gordura dos atletas com a seleção brasileira de 2002

\begin{tabular}{llll}
\hline & Seleção Brasileira 2002 & Atleta 1 & Atleta2 \\
Gordura corporal & $7,6 \%$ & $7,6 \%$ & $10 \%$ \\
\hline
\end{tabular}

CONEXÕES, revista da Faculdade de Educação Física da UNICAMP, Campinas, v. 6, ed. especial, p. 72-83, jul. 2008. ISSN: $1983-9030$. 


\section{ANÁLISE DO DESEMPENHO EM COMPETIÇÕES}

Atleta1, em 2001, sagrou-se: Campeão dos Jogos Regionais de São Paulo, campeão dos Jogos Abertos do Interior que apresenta um nível de importância, dificuldade e complexidade semelhante a um Campeonato Brasileiro, campeão da Copa Aurélio Miguel, que possui nível semelhante ao Campeonato Brasileiro Universitário, $3^{\circ}$ colocado no JUB's, campeão da Seletiva Aberta de São Paulo para o Campeonato Mundial, campeão da Seletiva Aberta Nacional para o Campeonato Mundial. Com estes resultados, se tornou membro da seleção brasileira permanente.

Quadro 6 - Comparação do número de classificações como semi-finalista em torneios antes da preparação física (2000) e durante (2001).

\begin{tabular}{|l|c|c|}
\hline Judoca - nível do torneio & $\mathbf{2 0 0 0}$ & $\mathbf{2 0 0 1}$ \\
\hline Atleta1 - federação nacional & $\mathbf{0}$ & $\mathbf{2}$ \\
\hline Atleta1 - federação estadual & $\mathbf{1}$ & $\mathbf{1}$ \\
\hline Atleta1 - federação regional & $\mathbf{0}$ & $\mathbf{1}$ \\
\hline Atleta1 - universitário nacional & $\mathbf{1}$ & $\mathbf{2}$ \\
\hline Atleta1 - universitário estadual & $\mathbf{1}$ & $\mathbf{0}$ \\
\hline Atleta 2 - federação estadual & $\mathbf{2}$ & $\mathbf{2}$ \\
\hline Atleta 2 - amistoso & $\mathbf{2}$ & $\mathbf{4}$ \\
\hline Geral Todos & $\mathbf{7}$ & $\mathbf{1 2}$ \\
\hline
\end{tabular}

Atleta 2, em 2001, ocupou o podium em torneios de caráter municipal e estadual. Campeão em Osasco, $3^{\circ}$ colocado no metropolitano, $3^{\circ}$ colocado no Paulistano, $3^{\circ}$ colocado na Budôkan, $3^{\circ}$ colocado em Bastos, $3^{\circ}$ colocado em Ibiúna.

Através da análise do desempenho em competições, pode-se dizer que a preparação física colaborou positivamente para o aumento do número de medalhas conquistadas por ambos os judocas. Em 2000 foram obtidas 7 medalhas pelos 2 judocas enquanto em 200112 foram ganhas. Ambos os judocas aumentaram o número de medalhas conquistadas. Atletal obteve expressivas conquistas em torneios de nível nacional que ainda não tinha alcançado na sua carreira atlética, enquanto o atleta2 manteve o número de medalhas conquistadas em nível estadual, mas aumentou em torneios amistosos.

\section{CONCLUSÕES}

Os resultados obtidos comparados à literatura científica e às avaliações particulares dos atletas sobre seus próprios desempenhos e os resultados obtidos, nos mostram que o presente planejamento de treinamento específico para a modalidade judô obteve sucesso em todos os objetivos propostos, entretanto, não se pode afirmar que este é um modelo a ser seguido por outros atletas. 
Cada atleta tem carências, potencialidades e objetivos específicos. Por este motivo foi desenvolvido um trabalho respeitando as características da categoria de peso, a individualidade do judoca em relação à sua forma de lutar e condição física, buscando diminuir as deficiências e aumentar as qualidades para melhorar o desempenho. O planejamento (periodização) em torno do calendário, da disponibilidade de tempo e dos materiais, assim como os objetivos bem definidos foram também pontos-chave para os ganhos alcançados:

Ganhos significativos em força $=21,3 \%$, manutenção do baixo percentual de gordura: $8,8 \%$ em média para ambos os judocas, em quanto a seleção brasileira apresenta $8 \%$ para a categoria até $60 \mathrm{~kg}$, aumento no número de medalhas: em geral $=71,42 \%$; atleta $1=100 \%$; atleta $2=50 \%$, conquista da vaga na seleção brasileira por um dos atletas. Sugerem-se outros estudos com atletas e categorias de peso diferentes devem ser avaliados para melhores conclusões.

\section{REFERÊNCIAS}

AZEVEDO, P. H. S. N. et al. Sistematização da preparação física do judoca Mario Sabino: um estudo de caso. Revista Brasileira de Ciências do Esporte, Porto Alegre, v. 26, n. 1, 2004.

CALLISTER, R. et al. A. Physiological and performance responses to overtraining in elite judo athletes. Medicine and Science in Sports and Exercise, Indianapolis, v. 22, n. 6, p. 816-24, 1990.

CASTARLENAS, J. L.; SOLÉ, J. El Entrenamiento de la resistencia en los deportes de lucha con agarre: una propuesta integradora. Apunts: Educación Física y Deportes, Barcelona, v. 47, p. 8186, 1997.

CASTARlENAS, J. L.; PLANAS, A. Estudio de la Estructura Temporal del Combate de Judo. Apunts: Educación Física y Deportes, Barcelona, v. 47, p. 32-39, 1997.

DANTAS; E.H.M., A Prática da preparação física. 5. ed. Rio de Janeiro: Shape, 2003.

EBINE, K. et al. Physiological characteristics of exercise and findings of laboratory tests in Japanese elite judo athletes. Medicine du Sport, v. 65, n. 2, p. 73-79, 1991.

FRANCHINI, E. Judô Desempenho competitivo. São Paulo: Manole, 2001.

FRANCHINI, E. et al. Estudo de caso das mudanças fisiológicas e de desempenho de judocas do sexo feminino em preparação para os Jogos Pan-Americanos. Revista Brasileira Ciência e Movimento, Brasília, v. 9, n. 2, p. 21-27, 2001.

FRANCHINI, E. et al. Características fisiológicas em testes laboratoriais e resposta da concentração de 
lactato em três lutas em judocas das classes juvenil-a júnior e sênior. Revista Paulista da Educação Física. São Paulo, v. 12, n.1, p. 5-16, 1998.

FORTESA DE LA ROSA, A. Treinamento desportivo: carga, estrutura e planejamento, São Paulo: Phorte, 2001.

KRAEMER, W. J. et al. Physiological and performance responses to tournament wrestling, Medicine and Science in Sports and Exercise, Indianapolis, v. 33, n. 8, p. 1367-1378, 2001.

LIMA, E, V. et al. Estudo da correlação entre velocidade de reação motora e o lactato sanguíneo em diferentes tempos de luta no judô. Revista Brasileira de Medicina e Esporte, Niterói, v.10, n.5, p.339343, 2004.

LITTLE, N. G.; Physical performance attributes of junior and senior women, juvenile, junior and senior men judokas. Journal of Sports Medicine and Physical Fitness, v. 31, p. 510-20, 1991.

SILVA, M. da. Caracterização do esforço em modalidades desportivas mensuráveis e não mensuráveis: O judô como caso exemplar. Treino Desportivo, Lisboa, n.10, p. 36-46, 1988.

TAYLOR, A.W.; BRASSARD, L. A physiological profile of the Canadian judo team. Journal of Sports Medicine, v. 21, p. 160-4, 1981.

THOMAS, S. et al. Physiological profiles of the Canadian national judo team. Canadian Journal of Sports Science, v. 14, n. 3, p. 142-147, 1989.

TSCHIENE, P. El ciclo annual de entrenamiento. Stadium, Buenos Aires, v. 21, n. 125, 1987.

TUMILTY, D. M. P. E.; HAHN, A.; TELFORD, R. D. A physiological profile of well-trained male judo players: with proposals for training. Excel, v. 2 n. 4, p. 12-14, 1986.

UMEDA, T. et al. Adverse effects of energy restriction on myogenic enzymes in judoists. Journal of Sports Science, Londres, v. 22, p. 329-338, 2004. 


\section{Felipe Leal de Paiva Carvalho.}

Laboratório de Biociências da Motricidade Humana - LABIMH - UCB/RJ

Estélio Henrique Martin Dantas.

Laboratório de Biociências da Motricidade Humana - LABIMH - UCB/RJ

Mauro Cesar Gurgel de Alencar Carvalho

MSC LAMCE/COOPE/UFRJ

LaCiMovi - Colégio Pedro II

Filipe Terada

UNIBAN/S.P.

Tiago Takara

Espaço 02/S.P.

\section{Referência do artigo:}

ABNT

CARVALHO et al. A preparação física de dois atletas de judô de alto nível estudo de caso. Conexões, v. 6, ed. especial, p. 72-83, 2008.

\section{APA}

Carvalho, F.L.P., Dantas, E. H. M., Carvalho, M. C. G. A., Terada, F., \& Takara, T. (2008). A Preparação física de dois atletas de judô de alto nível estudo de caso. Conexões, 6(ed. especial), 72-83 .

\section{VANCOUVER}

Carvalho FLP, Dantas EHM, Carvalho MCGA, Terada, F, Takara T. A Preparação física de dois atletas de judô de alto nível estudo de caso. Conexões, 2008; 6(ed. especial): 72-83. 